$$
\text { POE/PCPOC\%2- T2 }
$$

Contract Thte and Number:

Development of a Catalyst for Conversion

of Syngas-derived Materials to Isobutylene

DE-AC22-91PC90042

Contractor:

UOP

50 E. Algonquin Rd.

Des Plaines, IL 60017-5016

Contract Period: March 15, 1991 to March 14, 1994
Date: Oct. 3, 1991

Quartorly Roport No. 2

Reporting Perlod: 6/15/91-9/30/91

Author:

Gregory J. Gajda

DOE/PC/90042--T2

DE93 008189

\title{
QUARTERLY TECHNICALREPORT
}

Gasoline rsiormulation has become a priority throughout the refining industry. In most proposed new gasoline formulations, the addition of oxygenates, such as methyl tertiary butyl ether (MTBE), ethyl tertiary butyl sther (ETBE), or tertiary amyl methyl ether (TAME), is being considered to maintain an acceptable octane.

The production of the ethers MTBE and ETBE will ultimately be limited by the availability of isobutylene $\left(\mathrm{iC}_{4}{ }^{-}\right)$. Traditional commercial routes for producing $\mathrm{IC}_{4}{ }^{-}$will be unable to meet the large growth in demand anticipated for fuel ethers.

Developing a process in which coal could be converted to oxygenated gasoline blending components would take advantage of the vast coal reserves in the United States. The technology already exists for making methanol from coal-derived syngas. Numerous commercial processes are also available to make MTBE from methanol and $I C_{4}$ ". A new technology that could be used to make $\mathrm{iC}_{4}$ - from syngas would complement the syngas-to-methanol process, and help to ease the anticipated shortages of $/ \mathrm{C}_{4}{ }^{-}$.

The main goal of this contract is to develop a catalyst and technology that will produce $i C_{4}$ " directly from coal-derived syngas and that is capable of utilizing a lower $\left(0.5\right.$ to 1.0) $\mathrm{H}_{2}: \mathrm{CO}$ ratio. The research will identify and optimize the key catalyst and process characteristics that give improved performance for CO conversion by a non-Fischer-Tropsch process.

This report, which is the second quarterly report for contract DE-AC22-91PC90042, covers the testing of various $\mathrm{ZrO}_{2}$-based catalyst systems designed to examine the effects of catalyst 
preparation and process variables. Testing of precipltated $\mathrm{Z}_{2}$ powders indicates improved performance at lower calcination temperatures, which yield higher surface areas. Additional improvements are achieved with a sol-gel catalyst despite a lower surface area. The addition of $1 \%$ to the sol-gel catalyst had a small detrimental effect on selectivity.

\section{RESEARCHRESULTS}

\section{Catalyst Proparation}

The first catalyst, IS-1, was prepared following the general procedure used by Deflin, et al.' The catalyst was prepared by using ammonium hydroxide to precipltate $\mathrm{ZrO}_{2}$ from a solution of zirconyl chloride. The precipitate was filtered, washed with distilled water to remove residual chloride, and dried at $150^{\circ} \mathrm{C}$. The dried catalyst was calcined at $500^{\circ} \mathrm{C}$ for $2 \mathrm{hr}$ in flowing air. The calcined catalyst had a surface area of $63 \mathrm{~m}^{2} / \mathrm{g}$. Three additional calcination temperatures were also used. Calcining the dried catalyst at $450^{\circ} \mathrm{C}$ produced catalyst IS-2 with a surface area of $74 \mathrm{~m}^{2} / \mathrm{g}$. Similarly, calcining at $600^{\circ} \mathrm{C}$ produced catalyst $1 \mathrm{~S}-3$ with a surface area of $28 \mathrm{~m}^{2} / \mathrm{g}$, and calcining at $550^{\circ} \mathrm{C}$ produced catalyst $15-4$ with a surface area of $35 \mathrm{~m}^{2} / \mathrm{g}$. Two sol-gel catalysts were also prepared: IS-5, a pure $\mathrm{ZrO}_{2}$ calcined at $600^{\circ} \mathrm{C}$ with a surface area of 45 $\mathrm{m}^{2} / \mathrm{g}$, and IS-6, a $1 \%$ Y-ZrO2 catalyst calcined at $600^{\circ} \mathrm{C}$ with a surface area of $71 \mathrm{~m}^{2} / \mathrm{g}$.

\section{Catalyst Testing}

The catalysts were tested in the laboratory catalyst test system, described in Quarterly Report Nio 1. ${ }^{2}$ The catalyst was activated $450^{\circ} \mathrm{C}$ in flowing nitrogen in the laboratory test system. The catalyst was then reduced at $600 \mathrm{psig}$ and $450^{\circ} \mathrm{C}$ in flowing 1:1 $\mathrm{H}_{2}: \mathrm{CO}$ for $4 \mathrm{hr}$. Conversion and selectivity were measured at three combinations of temperature, pressure, and space velocity. These operating conditions were selected to give intermediate conversions (10-30\%). A detailed summary of each successtul run is given in the appendix.

Runs 2-4 were aborted because of coking problems. Sulfiding of the reactor prior to Run 5 appears to have cured the problem. Run 5 is a blank run to demonstrate the low background activity $\left(0.4 \% \mathrm{CO}\right.$ conversion). Runs $6-8$ are tests of precipitated $\mathrm{ZrO}_{2}$ catalysts calcined at $600^{\circ} \mathrm{C}$ (IS-3), $550^{\circ} \mathrm{C}$ (IS-4), and $500^{\circ} \mathrm{C}$ (IS-1), respectively. Run 9 is a sol-gel $\mathrm{ZrO}_{2}$ catalyst calcined at $600^{\circ} \mathrm{C}$ (IS.5) for comparison with Run 6, and Run 10 is a $1 \% \mathrm{Y} \cdot \mathrm{ZrO} \mathrm{O}_{2} 80 \mathrm{O}-\mathrm{gel}$ catalyst calcined at $600^{\circ} \mathrm{C}$ (IS-6) for comparison with Run 9. 
The CO conversion for Runs $5-10$ at the conditions of $450^{\circ} \mathrm{C}, 1,200 \mathrm{psig}$, and 1,920 GHSV, generally the maximum CO conversion conditions for each run, is given in Table 1. In general, the conversion increases with increasing surface area for the precipitated $\mathrm{ZrO}_{2}$ 's but is systematically higher for the sol-gel catalysts. The $1 \% \mathrm{Y} \cdot \mathrm{ZrO}_{2}$ catalyst has the highest conversion. The selectivity to $\mathrm{IC}_{4}{ }^{-}$versus $\mathrm{CO}$ conversion is plotted in Figure 1. In general, the selectivity decreases with increasing conversion, except at low conversion were little $/ C_{4}{ }^{-}$is produced. The sol-gel $\mathrm{ZrO}_{2}$ catalyst is more selective than the precipitated catalysts, but the $1 \% \mathrm{Y}-\mathrm{ZrO}_{2}$ catalyst is less selective (as a result of increased $\mathrm{CH}_{4}$ production). The combination of high activity and selectivity for the sol-gel $\mathrm{ZrO}_{2}$ catalyst gives an $\mathrm{IC}_{4}{ }^{-}$yield of $2.2 \%$, which is comparable to the best literature values for an unmodified $\mathrm{ZrO}_{2}$ of $1.7 \%$ reported by Deflin, et al.'

Table 1

Conversion of $\mathrm{CO}$ at Standard Conditions

\begin{tabular}{|c|l|c|c|c|}
\hline Catalyst & \multicolumn{1}{|c|}{ Description } & Run & Surface Area & CO Conversion \\
\hline \hline blank & & 5 & - & 0.4 \\
\hline IS-3 & $\mathrm{ZrO} 2,600^{\circ} \mathrm{C}$ & 6 & 28 & 4.9 \\
\hline IS-4 & $\mathrm{ZrO}, 550^{\circ} \mathrm{C}$ & 7 & 35 & 15.3 \\
\hline IS-1 & $\mathrm{ZrO} 2,500^{\circ} \mathrm{C}$ & 8 & 63 & 17.5 \\
\hline IS-5 & $\mathrm{ZrO2}, 501-\mathrm{gel}, 600^{\circ} \mathrm{C}$ & 9 & 45 & 23.9 \\
\hline IS-6 & $1 \%$ Y-ZrO2, $501-g e l, 600^{\circ} \mathrm{C}$ & 10 & 71 & 26.4 \\
\hline
\end{tabular}

\section{EUTURE WORK}

The preliminary evaluation of catalysts will consist of two phases. In the first phase of catalyst evaluation, materials that have been previously reported for the selective production of branched $\mathrm{C}_{4}$ products from synthesis gas, such as IS-1, will be reproduced and tested. The testing will provide a base of catalyst performance data that can be used for the direct comparison of different catalyst systems.

In the second phase of catalyst testing, new formulations will be evaluated to identify approaches for the development of a catalyst with performance exceeding that of previously described materials. Specific performance factors to be emphasized are catalyst activity and 


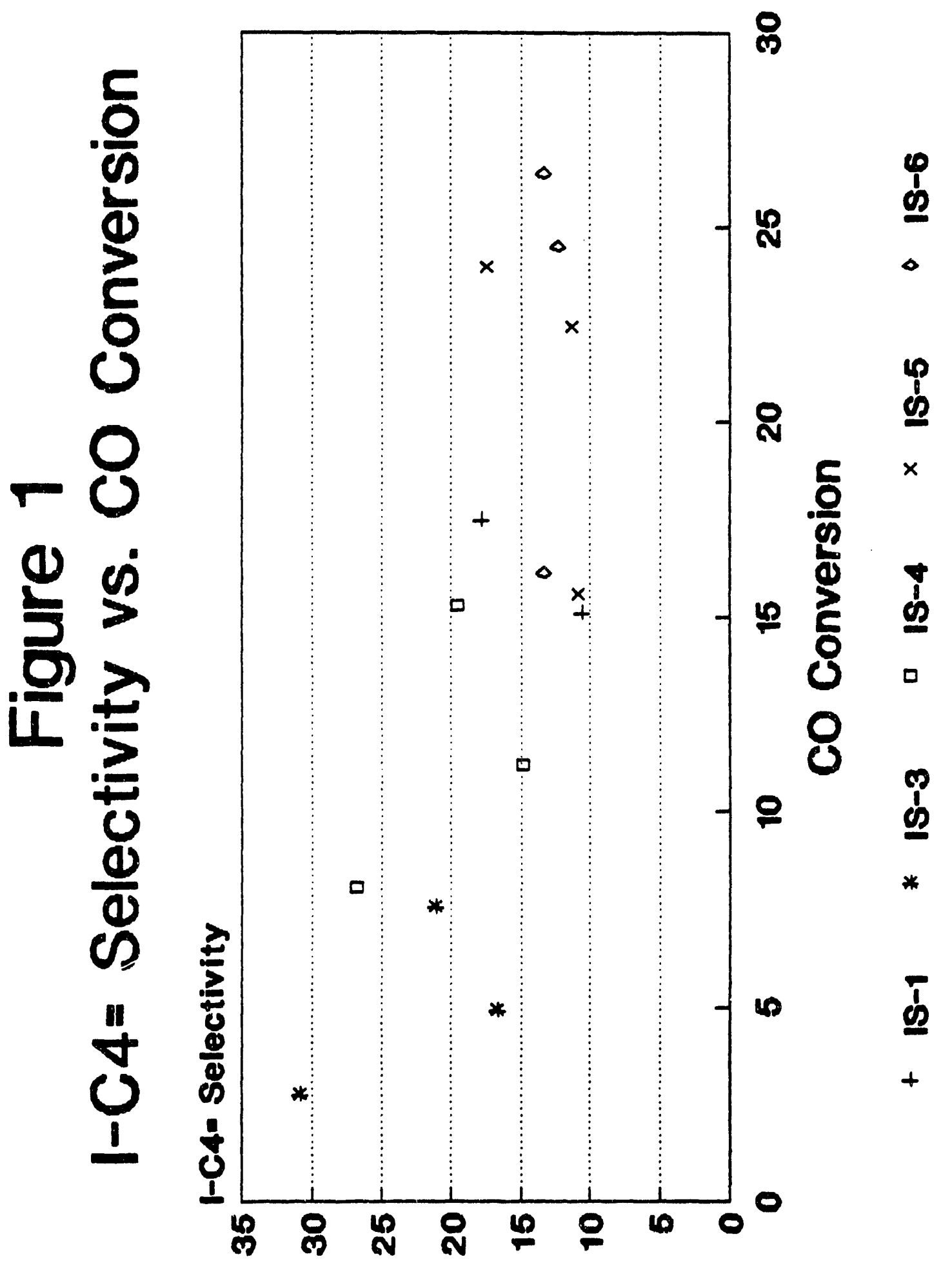


selectivity to $C_{4}$ branched products rather than $C_{1}-C_{3}$ lights and saturated by-products. The primary goal will be to identify relationships between catalyst properties and performance for synthesis gas conversion. Based on this understanding, further catalyst improvements can be developed.

The use of new methods for the preparation of metal oxide catalysts with improved properties such as regulation of crystallite size, increased uniformity throughout the metal oxide particle, and increased surface area is another approach that will be investigated. Variation of precipitation methods for the control of the metal oxide structure, the use of sol-gel technology for the preparation of metal oxide materials (such as 1S-5), and supported metal oxide catalysts will be examined to achieve these goals.

In the next quarter, we plan to evaluate the effect of basic catalyst additives $(\mathrm{Na}, \mathrm{Ba}, \mathrm{Cs})$ on $\mathrm{ZrO}_{2}$-based catalysts. Lterature reports claim improved selectivity for more basic catalysts.' In addition, the testing of sol-gel catalysts calcined at lower temperatures and the evaluation of $\mathrm{CeO}_{2}$ catalysts are plarined.

\section{REFERFNCES}

1. M. Deflin, J. C. Lambert, and P. E. Dejaitve, Canadian Patent $1,226,875$

(1987).

2. P. T. Barger and G. J. Gajda, Quarterly Report No. 1, (1991). 


\section{APPENDIX}

\section{Run Summaries}




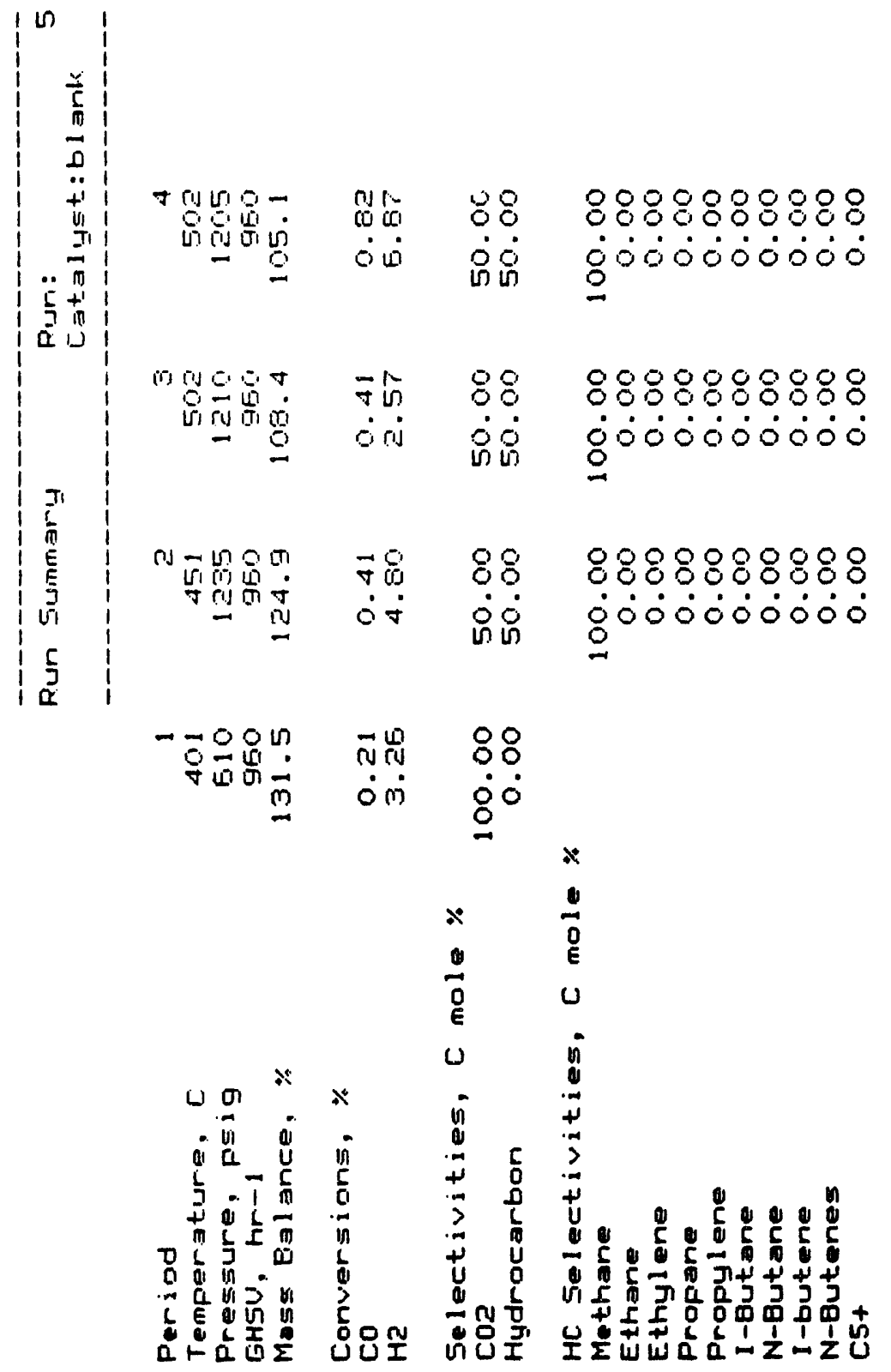




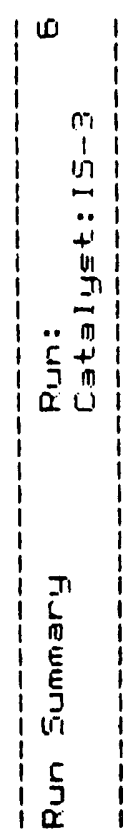

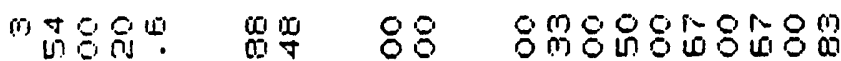

然向

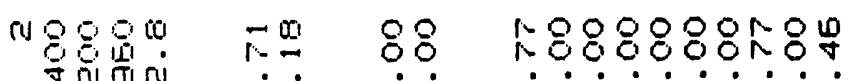

जू nui

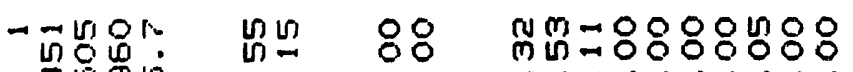

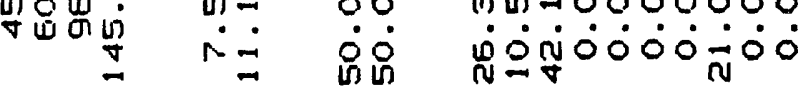

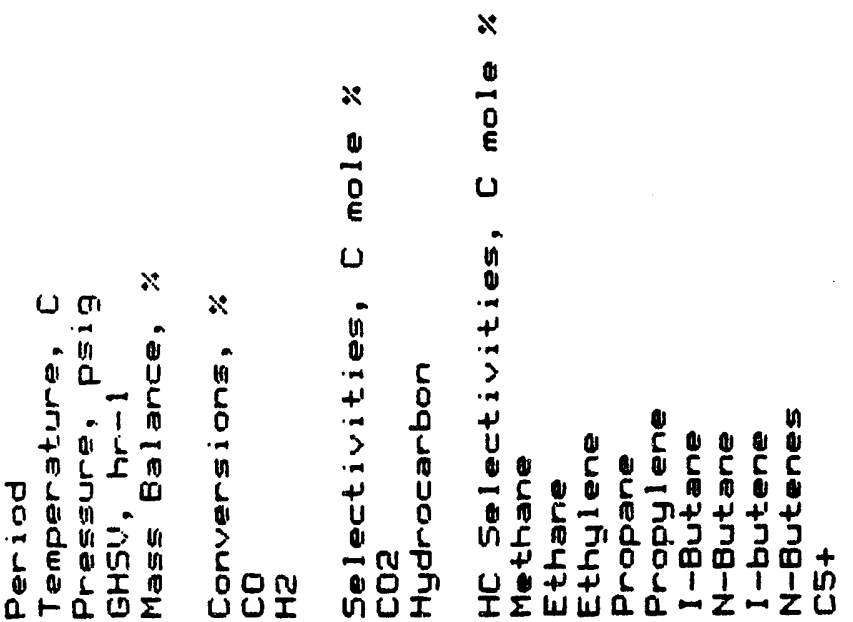




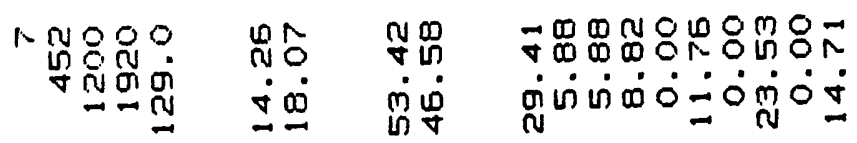

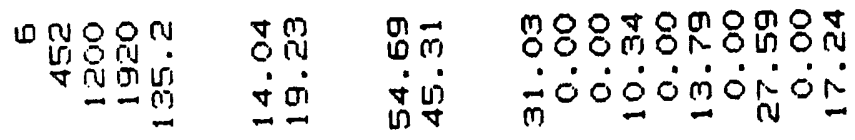

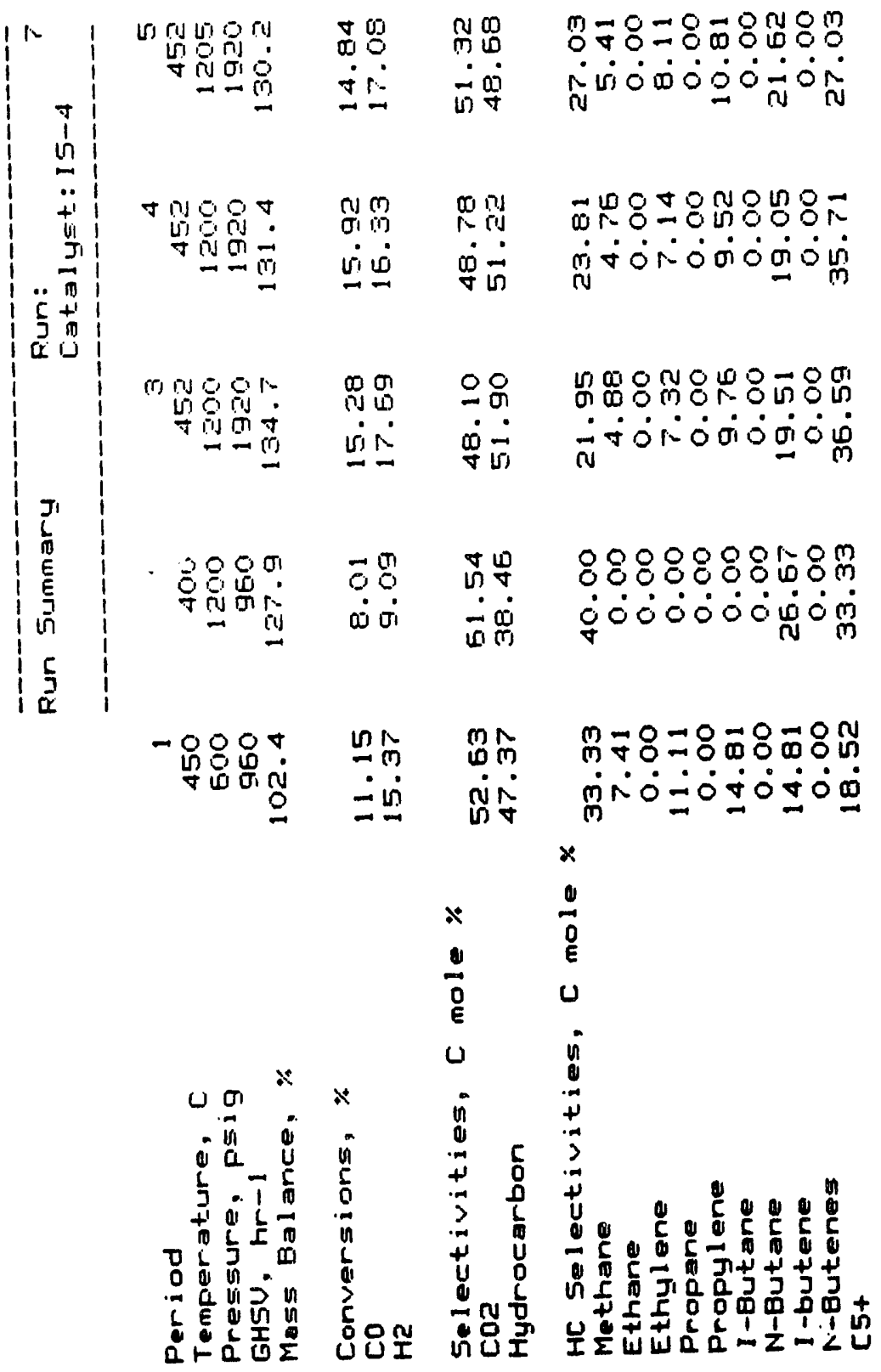




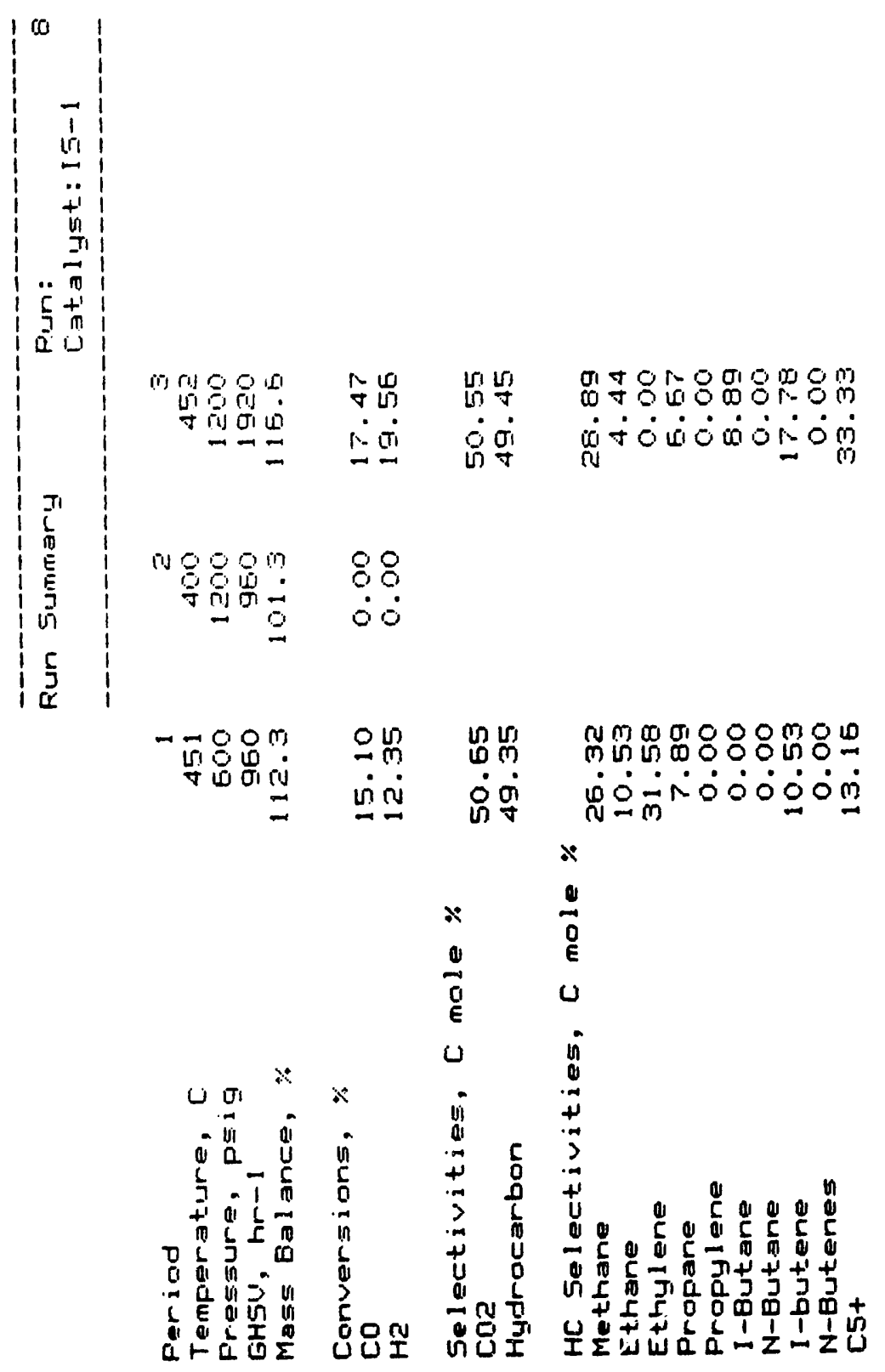




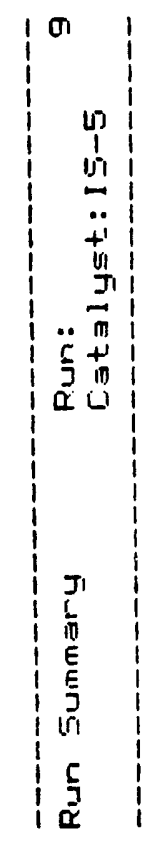

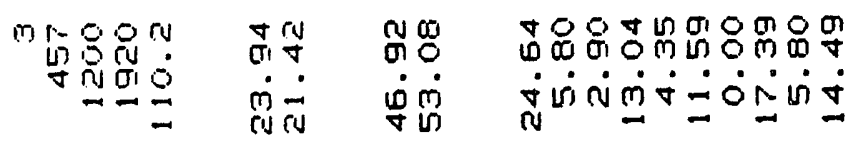

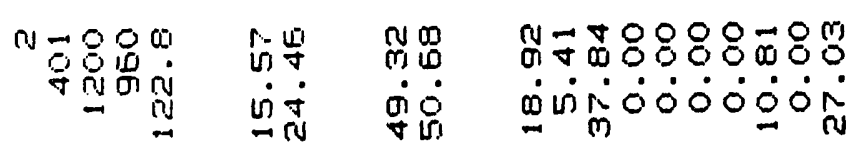

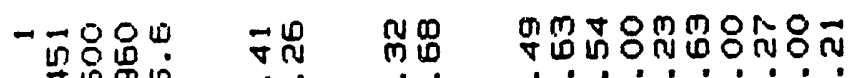

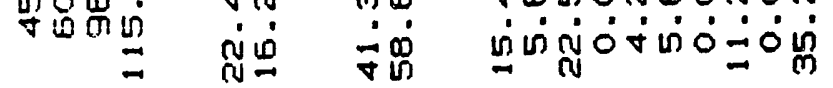

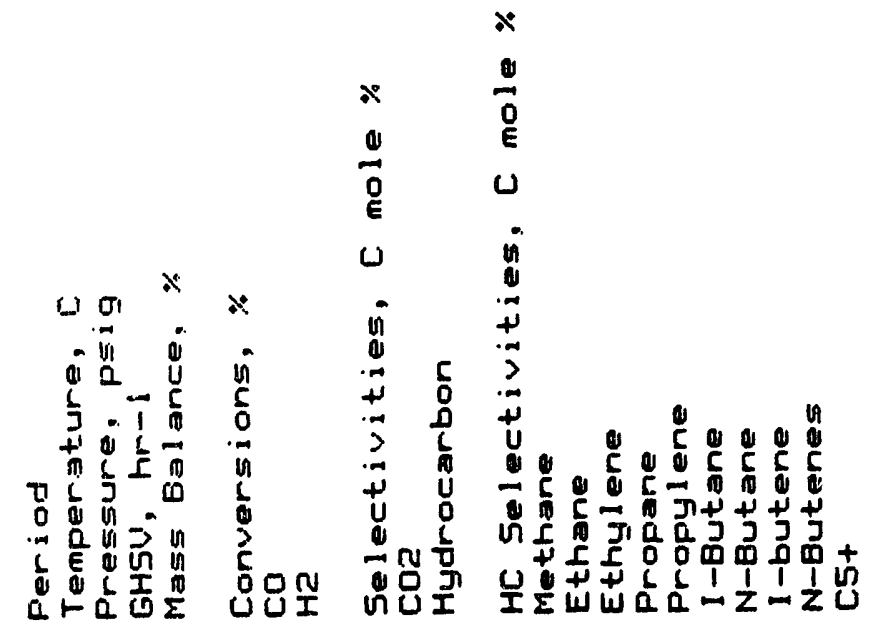




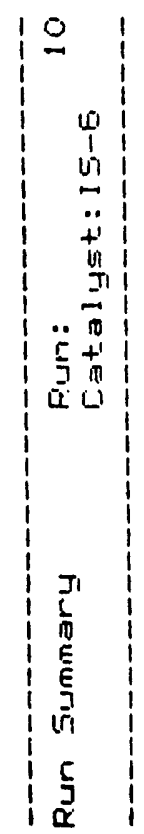

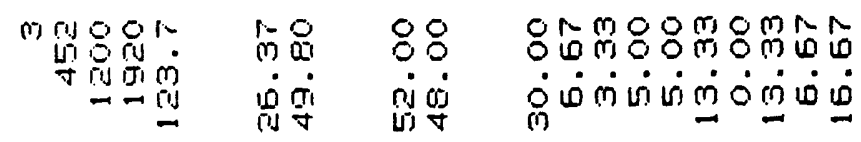

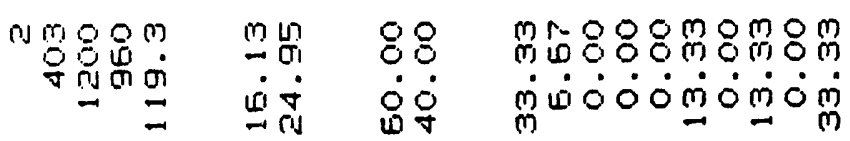

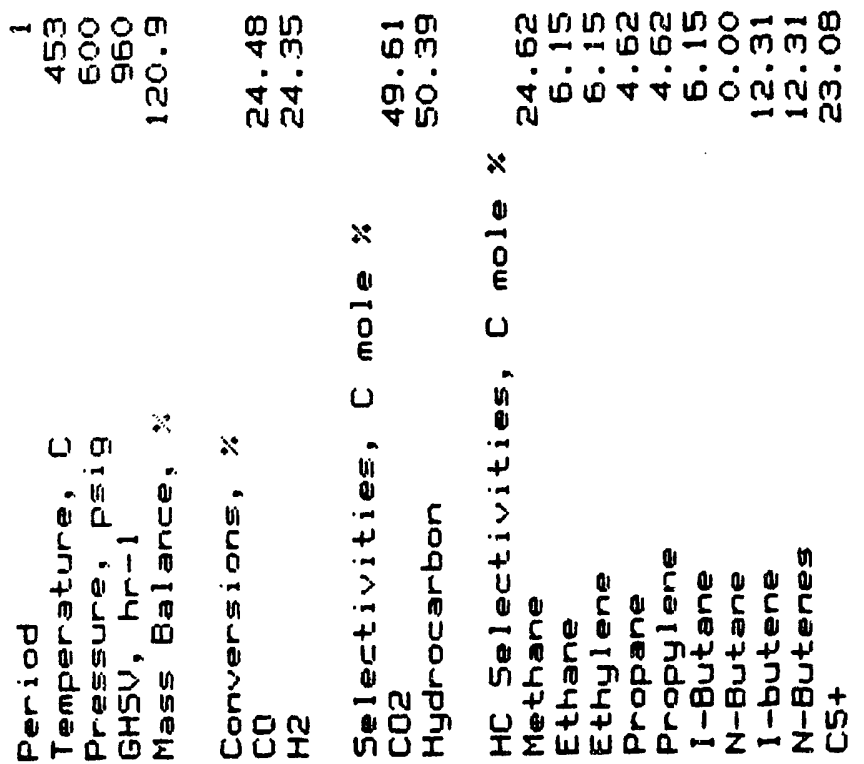



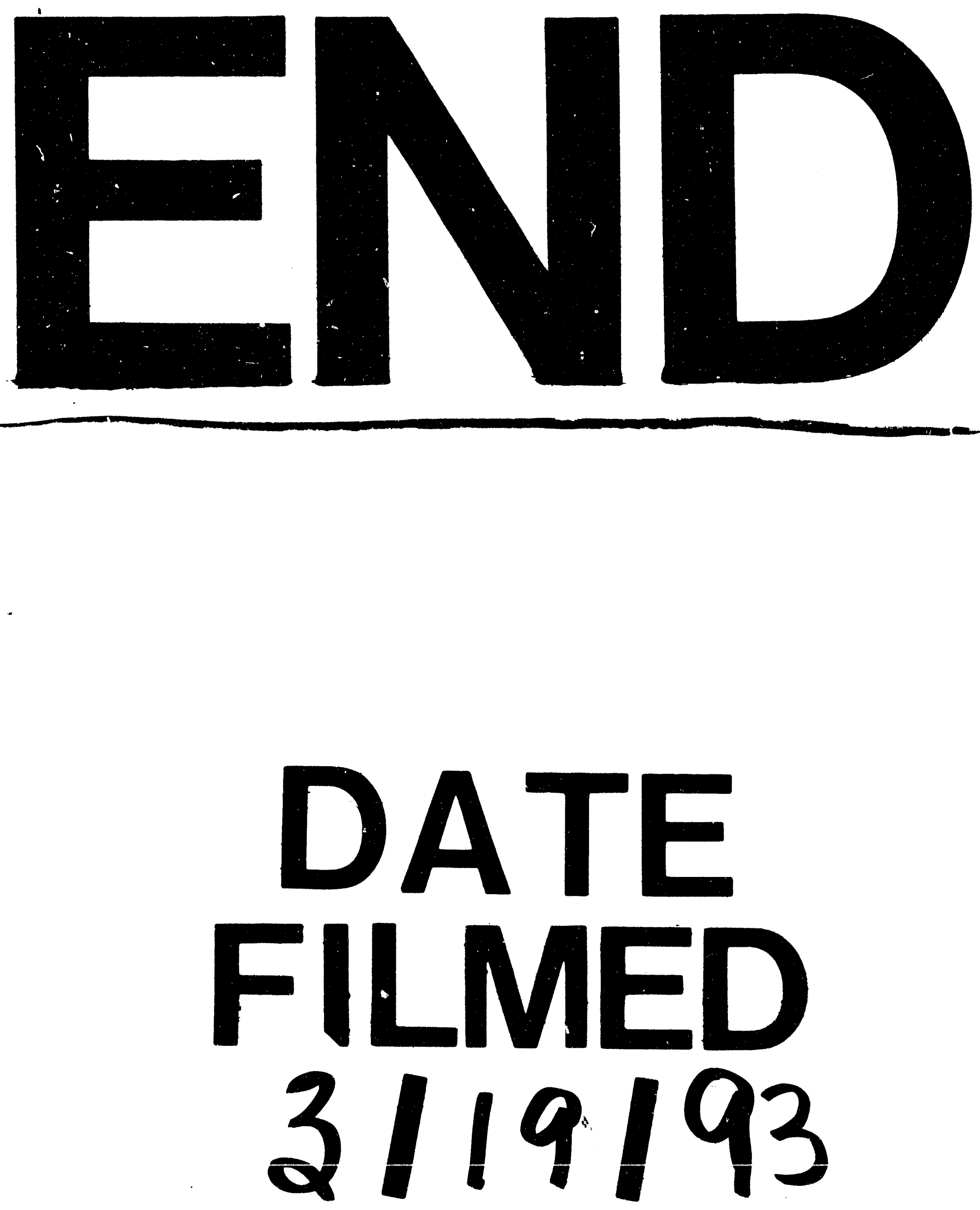
